UDK 528.085.421

\title{
RESEARCH OF THE ANGULAR POSITIONING ACCURACY OF THE EXPERIMENTAL TEST BENCH
}

\author{
Vytautas Giniotis ${ }^{1}$, Domantas Bručas ${ }^{2}$ \\ ${ }^{I}$ Institute of Geodesy, ${ }^{2}$ Dept of Geodesy and Cadastre, Vilnius Gediminas Technical Uuniversity, \\ Sauletekio al. 11, LT-10223 Vilnius-40, Lietuva \\ e-mail:vg@ai.vtu.lt
}

Received 2001 2006, accepted 17032006

\begin{abstract}
Most geodetic instruments are based on measurement of angular values. Such instruments as digital theodolites, total stations etc are used in geodesy, building structure, surveying, in machine engineering etc. Preliminary research of the accuracy of the test rig created for precise angular measurements is presented here. Visual angular scale accuracy measurements are given and some statistical parameters of measuring data are evaluated. Conclusions for further development of the test rig are formulated.
\end{abstract}

Keywords: circular scale, measurement, evaluation, accuracy, uncertainty.

\section{Introduction}

Digital levels, theodolites, total stations etc are used in geodesy, surveying, machine engineering and other branches of industry. Geodetic instruments display a great number of discrete values on their display units during measurement, and these values must also be checked during calibration $[1,2]$.

Calibration of these instruments is performed using multiangular prisms - polygons with an autocollimator, rotary tables, circular scales and reference length measures. The angle and length measures are calibrated against the upper level measures (etalons) in a way ensuring traceability of measurements. Length measurements are more widely implemented and this is not as well organised with angle measurements. The methods of calibration of constant angle value in full circle are used in many angular measurements at the restricted number of angular values. At the same time, geodetic instruments have a great number of discrete values that are indicated on their display units during the measurements. Some widely accepted and new methods [2-6] of angle measurement also can be used for this purpose. Uncertainty problems for assessing a restricted number of angular positions measured are discussed and the solution proposed $[5,7]$.

Preliminary research of the accuracy of the test rig created for precise angular measurements is presented here. Visual angular scale accuracy measurements are given and some statistical parameters are evaluated.

\section{The methods of circular scale calibration}

There are several accuracy specifications of geodetic instruments that state their metrological features. For example, some technical parameters of many types of geodetic instruments are as follows:

- $\quad$ values of circular scale's division: $1^{\circ} ; 20^{\prime}$;

- accuracy of readings from a circular scale: $0,5^{\prime} ; 0,1^{\prime} ; 15^{\prime \prime} ; 1$ "; 0,2";

- $\quad$ standard deviation of angle measurement

$$
1,5^{\prime \prime} 0,5^{\prime \prime} \text {. }
$$

It shows a high accuracy of measurements by precise instruments, so a higher level of accuracy calibration of such instruments is needed. The accuracy data presented above forces one to apply a measurement standard for calibration purposes of a higher accuracy than the accuracy of an instrument itself.

Some descriptions of the angular calibration are presented [8-11]. The calibration can be performed using the Moore's 1440 Precision Index as angle standard and angle polygon prism of 12 sides with the autocollimator. Moore's 1440 Precision Index is an angular measuring device consisting of two serrated plates joining together to create the angle standard of measure. During the measurement the upper disk of the Index is lifted, the lower part rotates with the object to be measured, after that the upper part is lowered back and the readings of the angular position bias is performed by the autocollimator. The authors [10] describe the results of the mutual calibration process of the Moore's 1440 Precision Index and the polygon. The repeatability of the readings of the autocollimator was not exceeding $\pm 0,02^{\prime \prime}$. The accuracy of axis of Index rotation was $0,11 \mu \mathrm{m}$, the interval of angle measurements was $30^{\circ}$. Every position was repeated 10 times, the values of polygon calibration were in the limits between $\left(-1,6^{\prime \prime}\right.$ and $\left.+2,7^{\prime \prime}\right)$. Theoretical aspects of two calibration methods are discussed. The angular correction values are 
determined and mean standard deviations of the calibration are presented.

The tests for accuracy of the comparator for the flat angle unit transfer were carried out in PTB, Germany [12]. The angular comparator WMT 220 of a very high accuracy was used for the calibration of electronic autocollimators for the flat angle unit, radian, transfer according to the ISO standards. An uncertainty of 0,007 " was determined as the result of calibration of the electronic autocollimators of high resolution in repeating the consecutive steps of $0,005^{\prime \prime}$ in the transfer of the standard unit of flat angle. It was stated that the calibration by very small intervals that are near the resolution capability of the autocollimator gives an information about the possible short period bias and, consequently, making the influence to the effect of measurement by the autocollimator.

This short review shows an importance and significance of circular scales calibration and a complexity of this task having in mind a small number of reference angle measure that is in case of using polygon as the standard measure.

\section{Measurement of circular scale's error}

In the metrology of circular scales that was mostly developed in geodesy and astronomy there is such terminology used as "error of the scales diameter". This expression of "diameter" means the line going through the strokes lying on the opposite side according to the scale centre. In most geodetic measurements the errors of "diameters" or angle errors between the "diameters" are determined. It helps to avoid the errors due to the eccentricity of the scale to be measured and the trajectory of axis rotation. The error of "diameters" is expressed by the algebraic sum of errors of two opposite strokes [1,2]:

$$
\Delta\left(\varphi_{\Sigma}^{i}\right)=\Delta \varphi_{\Sigma}^{i}+\Delta \varphi_{\Sigma}^{i+180^{\circ}}
$$

where $\Delta \varphi_{\Sigma}^{i}$ ir $\Delta \varphi_{\Sigma}^{i+180^{\circ}}$ are the errors of two opposite strokes.

The errors of circular scales are determined by some methods approved in written standards:

- the method of approximation;

- the method of opposite matrix;

- the method of Yeliseyev (or Heuvelink);

- the method of Wild.

These methods are legalised by the written standard [9], the exception being that the method of Heuvelink is used more widely in the West European countries. Mostly they are used to determine the scale's "diameters" error.

The test rig used in this research consists of basic part, drive, rotary encoder, reference measure and the measuring instruments [13]. The scale to be calibrated is made on the warm wheel of the drive. It is connected to the axially fixed rotary encoder that generates the pulses of an angular value of $\Delta=2 \pi r / n$ during rotation of the wheel. Also in the axis of rotation a reference measure - polygon is fixed. The readings $\Delta \varphi_{a i}$ of the polygon are taken by the photoelectric autocollimator. The photoelectric microscope readings set on the scale $\Delta \varphi_{m i}$ are also taken at the same angular position of the wheel and the polygon. The polygon has 12 flat edges at every $30^{\circ}$ angular positions.

A sequence of measuring data registration and processing is as follows. Angular error of the $i^{\text {th }}$ stroke of the scale is expressed as

$$
\delta \varphi_{i}=\Delta \varphi_{m i}-\Delta \varphi_{a i}
$$

where $\Delta \varphi_{m i}$ are the readings of the microscope (angular position of the stroke of circular scale) and $\Delta \varphi_{a i}-$ reference angular position readings of the autocollimator. Pulses $\Delta$ of the rotary encoder are used only to control the drive for the rotating the scale into the required angular position.

Further data processing includes typical statistical operations - mean values, standard deviation, systematic error (bias) and uncertainty determination. An example of measuring result of the scale calibration is shown in the Table.

Assuming the normal distribution law of the readings of photoelectric microscope and autocollimator during the measurement of the scale, let us verify how allowable the differences between the estimates of the dispersions between these measurements are. It is the main item to investigate as the test rig was newly developed and operators performing the visual measurements had a little experience in measuring.

At first, comparing the estimates of the dispersions between two groups of readings is performed. The purpose is to evaluate the readings got by two different operators and two different instruments. The criterium of R. Fisher [14] here was applied.

Example of the scale calibration result

\begin{tabular}{|c|c|c|c|}
\hline $\begin{array}{c}\text { Circular } \\
\text { scale } \\
\text { position, } \\
\left({ }^{\circ}\right)\end{array}$ & $\begin{array}{c}\text { Mean scale } \\
\text { bias } \\
\text { (calculated), } \\
\text { sec }\end{array}$ & $\begin{array}{c}\text { Number } \\
\text { of } \\
\text { readings }\end{array}$ & $\begin{array}{c}\text { Uncertainty, } \\
\text { sec }\end{array}$ \\
\hline 0 & 0,00 & 22 & 0,0000 \\
30 & $-1,22$ & 23 & 0,4777 \\
60 & 0,70 & 22 & 0,4394 \\
90 & 1,40 & 19 & 0,4897 \\
120 & 2,94 & 23 & 0,3570 \\
150 & 1,72 & 21 & 0,3307 \\
180 & 0,91 & 20 & 0,5016 \\
210 & 0,80 & 23 & 0,3797 \\
240 & 0,78 & 23 & 0,3145 \\
270 & $-25,56$ & 20 & - \\
300 & $-0,528$ & 21 & 0,4213 \\
330 & $-0,641$ & 23 & 0,3218 \\
360 & 0,300 & 21 & 0,3553 \\
\hline
\end{tabular}


Dispersions of these readings will be $S_{1}^{2}$. and $S_{2}^{2}$. Number of readings in the sets is $n_{1}$ and $n_{2}$, so the numbers of the degrees of freedom $k_{i}$ will be $\left(k_{l}=n_{1}-1\right)$ and $\left(k_{2}=n_{2}-1\right)$. As the readings were of the same object and at the same pitch of angle positions,

$k_{1}=k_{2}$. After calculating the proportion

$$
F=\frac{S_{m}^{2}}{S_{a}^{2}}
$$

shows the value $\sim 2$, and checking of its value in the tables $(3,44)$ at the number of degrees of freedom 8 and probability level 0,95$)$, we have determined an acceptable hypothesis of the dependence the estimates of both dispersions on the same value of the dispersion. The values of uncertainty at $270^{\circ}$ were not calculated as they are going outside of the acceptable values of sample chosen. The standard deviation of sample is 0,534 . It is at the level of the standard deviation of angle measurement by geodetic instruments mentioned in Chapter 2 of this article.

A little more complicated case is by evaluation of all the measurement of the full scale as it is shown in Fig 1.

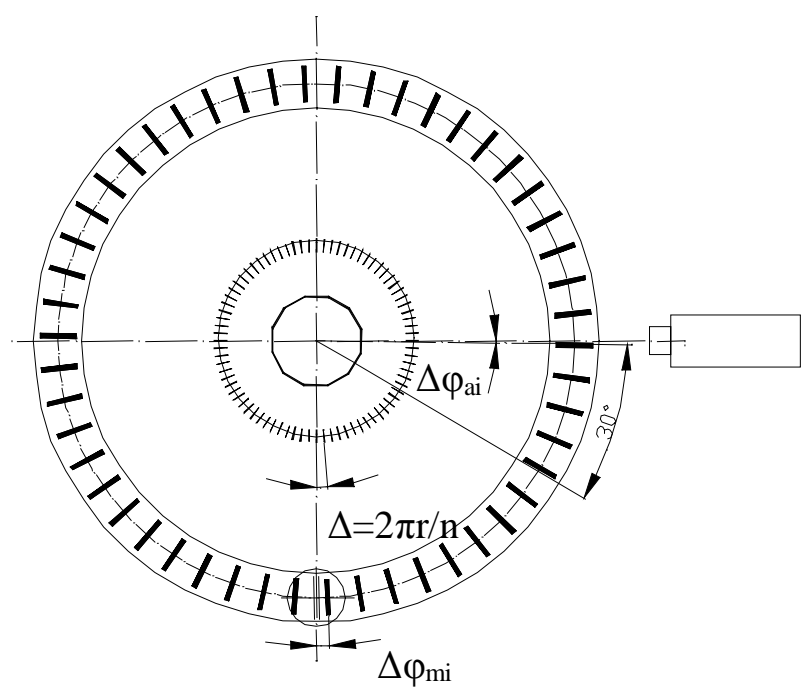

Fig 1. The diagram of circular scale calibration

There we must apply the criterion of M. Bartlet [14] where an assessment of dispersions of several groups of trials can be performed:

$$
M=N \ln \left(\frac{1}{N} \sum_{i=1}^{L} K_{i} S_{i}^{2}\right)-\sum_{i=1}^{L} k_{i} \ln S_{i}^{2},
$$

where

$$
N=\sum_{i=1}^{L} k_{i}
$$

If a hypothesis of equality of the dispersions is valid, then a proportion

$$
\chi_{1}^{2}=\frac{M}{1+\frac{1}{3(L-1)}\left(\sum_{i=1}^{L} \frac{1}{k_{i}}-\frac{1}{N}\right)}
$$

will be distributed approximately as $\chi^{2}$ at $(L-1)$ number of degrees of freedom. At the selected level of significance $q$ we find a value of $\chi_{q}^{2}$, and a condition $P\left\{\chi^{2} \triangleright \chi_{q}^{2}\right\}=q$ is verified.

If $\chi_{1}^{2}<\chi_{q}^{2}$, then an assumption can be maded that the difference between the dispersions is allowable. The data of measurements were used from Table of the readings. The calculations show the value of $\chi_{1}^{2}=14,22$ and a value of $\chi_{q}^{2}=12,338$ at a probability level 0,95 . It means that the difference between the dispersions of measurements performed is allowable.

The graphical view of measurements performed are shown in Figs 2, 3 and 4. In Fig 2 the scale readings are given, it is, the values $\Delta \varphi_{m i}$. The readings of an autocollimator $\Delta \varphi_{a i}$ are shown in Fig 3, and the scale's systematic error is calculated according to (2) and depicted in Fig 3. The circular scales "diameter" errors also can be calculated by (1) and the data of the systematic angle error. It can be noted that the curves in Figs 2, 3 could be processed by spectral analysis eliminating the first harmonic that depends on the eccentricity of the scale in respect of the rotation axis.

The measurement results show a statistical validity of the measurements performed. Nevertheless, there are several items that must be noted and taking into consideration for further development. At first, although all measurements belong to the same group of sample values determined by dispersion criteria, the standard deviation of measurements is quite big. It means that visual readings of the instruments must be improved and its scatter must be less. An automatisation of the reading process would improve a quality and accuracy of measurement.

Second, at this stage a systematic error or uncertainty of reference angle fixed by polygon is not assessed in the calculations. There is also one of the parameters of possible measurement accuracy improvement. Third, the scale position at $270^{\circ}$ must be investigated. A significant bias error at this point of angle could be as a result of a bad quality of the stroke on the scale or some defects on the scale's surface that influence the photoelectric scale readings. 


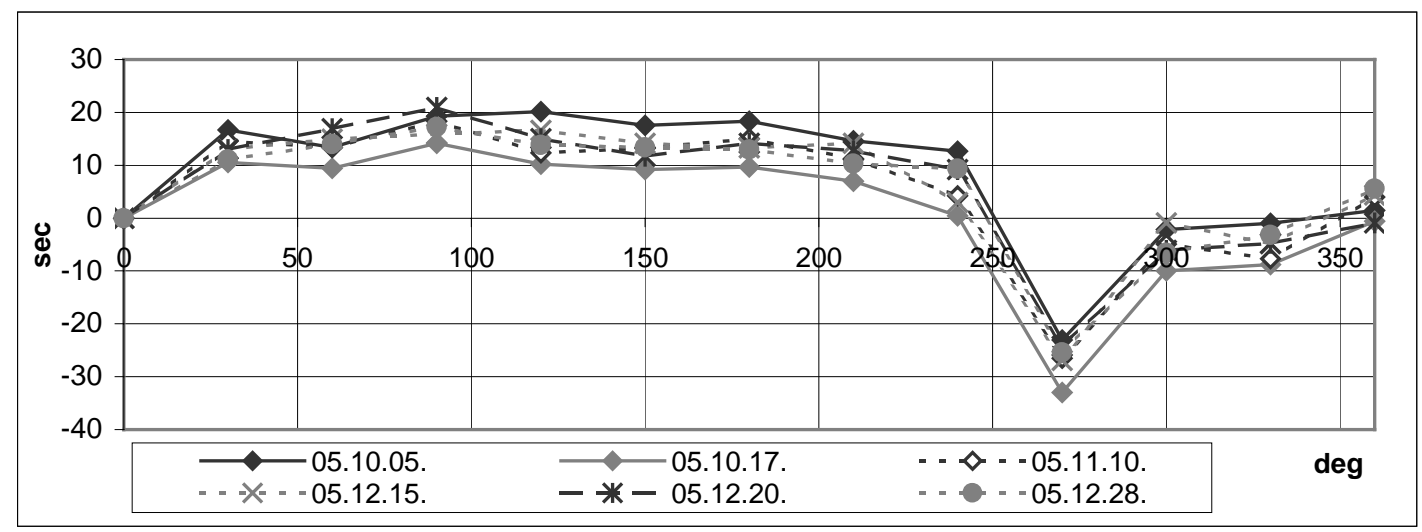

Fig 2. Graphs of readings of the photoelectric microscope (different dates)

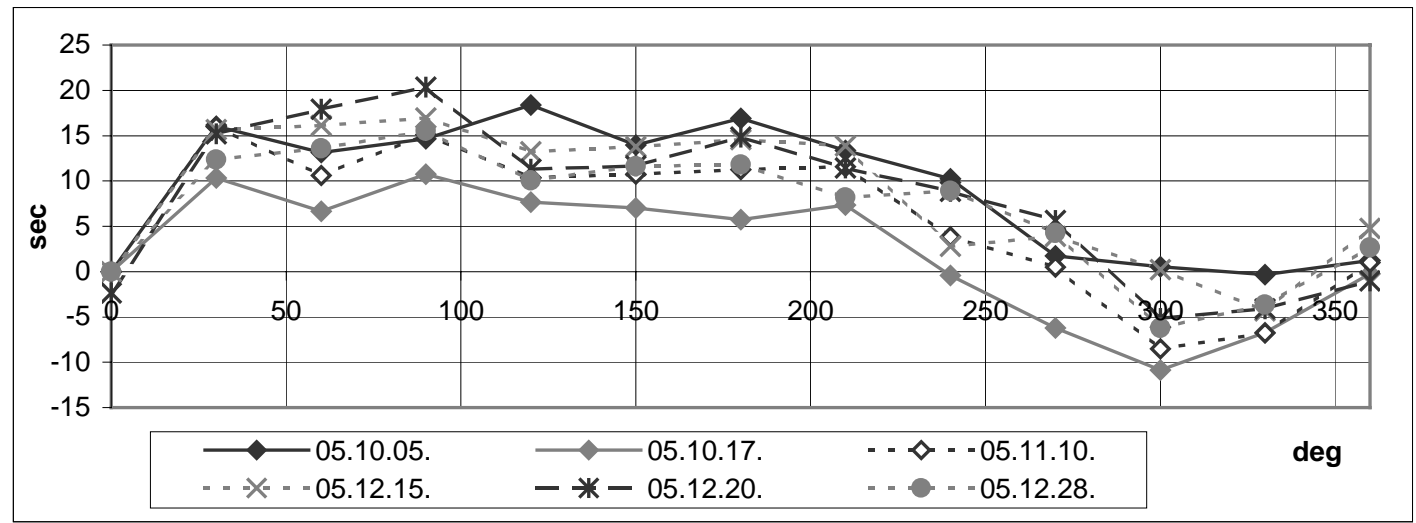

Fig 3. Graphs of readings of the photoelectric autocollimator (different dates)

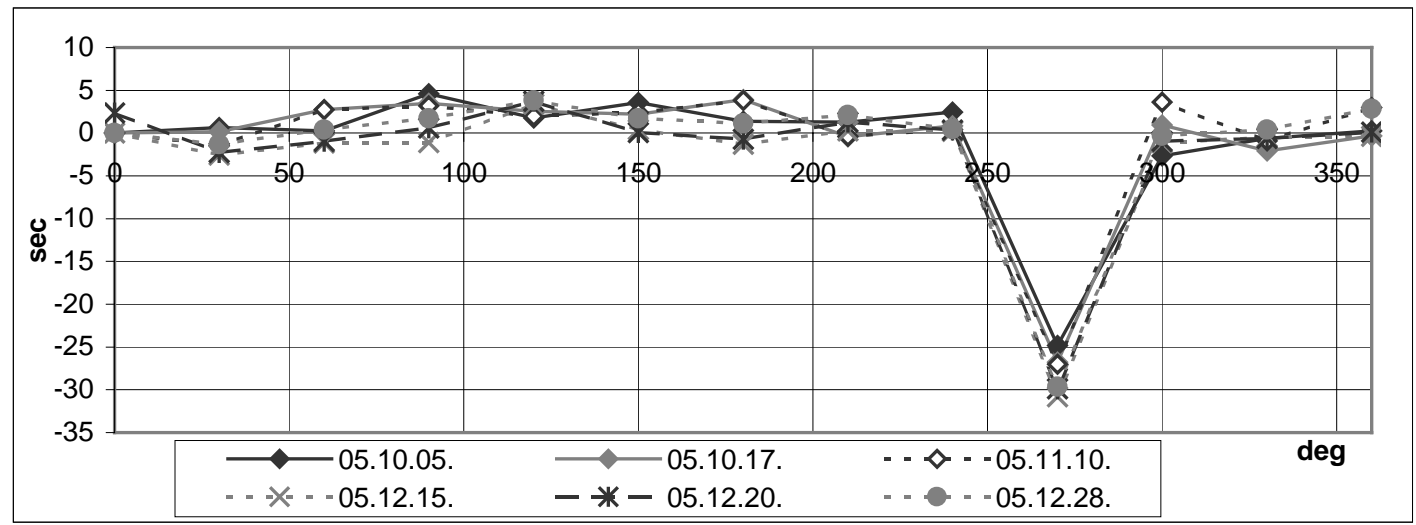

Fig 4. Systematic error of the scale determined by the readings of the microscope and autocollimator (different dates)

\section{Conclusions}

1. Practical trials of circular scale calibration are demonstrated. The test rig proposed has wide possibilities for automation and data evaluation by computer.

2. A background has been created for a higher accuracy performance testing of geodetic instruments.

3. Practical results of statistical evaluation of the results of measurement are given, the preliminary results showing an acceptable validity level of visual measurements.
4. The data presented lead to the conclusion that further test rig development and automatisation of measurement would improve an accuracy and save the time of measurements.

\section{References}

1. ISO 17123-3: Optics and optical instruments - Field procedures for testing geodetic and surveying instruments - Part 3: Theodolites. 2001. 
2. Jelisejev, S. V. Geodetic instruments and devices. Basic principles of design, calculations and production features. Moscow: Nedra, 1973. 392 p. (in Russian).

3. Giniotis, V. Brief review of methods for measuring of circular scales. Geodesy and Cartography (Geodezija ir kartografija), Nr. 2 (26), Vilnius: Technika, 1997, p. 21-25.

4. Just, A.; Krause, M.; Probst, R. and Wittekopf, R. Calibration of high-resolution electronic autocollimators against an angle comparator. Metrologia, 40, 2003, p. 288-294.

5. Giniotis, V. and Grattan, K. T. V. Optical Method for the Calibration of Raster Scales. Measurement, 32/1, 2002, p. 23-29.

6. Giniotis, V. and Rybokas, M. Data processing and information assessment in scales measurement simulation. In: Proceedings of XVII IMEKO World Congress, 2003, p. 1053-1056.

7. Giniotis, V.; Rybokas, M.; Petroškevičius, P. Investigations into the accuracy of angle calibration. Geodesy and Cartography (Geodezija ir kartografija), No 3 (30), 2004, p. 65-70.

8. Giniotis, V.; Grattan, K. T. V.; Rybokas, M.; Kulvietiene, R. Uncertainty analysis using information entropy. VDI - Berichte, No 1860, 2004, p. 505-510.

9. GOST 13424. Theodolites. Methods for determination of errors of horizontal circle diameter. Moscow: Nedra, 1983. 102 p. (in Russian).

10. Jablonski, R.; Shimokohbe, A. and Nagai, A. Calibration system for precision angle standards. Bull. P. M. E. (T. I. T.), No 45, 1980, p. 17-24.

11. Cook, A. H. The calibration of circular scales and precision polygons. Br. J. Appl. Phys., 5, 1954, p. 367371.

12. Just, A.; Krause, M.; Probst, R. and Wittekopf, R. Calibration of high-resolution electronic autocollimators against an angle comparator. Metrologia, 40, 2003, p. 288-294.

13. Rybokas, M.; Giniotis, V.; Petroškevičius, P.; Kulvietiene, R.; Bručas, D. Performance and Accuracy Monitoring of Geodetic Instruments. In: Proc of the Intern Conf on Condition Monitoring held at Kings College, Cambridge, UK, $1821^{\text {st }}$ July 2005, p. 167172.

14. Rabinovich, S. G. Errors of measurements. Leningrad: Energija, 1978. 262 p. (in Russian).
Vytautas Giniotis. Prof, Doctor Habil. Vilnius Gediminas Technical University. Institute of Geodesy.

$(\mathrm{Ph}+3705274$ 4705, Fax +370 5274 4705).

Author of one and co-author of epy other monograph and more than 160 scientific papers. Participated in many intern conferences, research and lecture visits to Germany, Austria and UK universities.

Research interests: 3D measurements and instrumentation, automatisation of measurements, angular measurements.

Domantas Bručas. Doctoral student at the Dept of Geodesy and Cadastre, Vilnius Gediminas Technical University. $(\mathrm{Ph}+3705274$ 4705, Fax +370 5274 4705).

Author of 4 scientific papers. In 2005 visited Institut für Geodäsie und Photogrammetrie, Eidgenössische Hochschule Zürich under the grant of Gerbert Ruf Foundation.

Research interests: development of comparator for angular measurements, automation of the processing of measurements results.

\section{EKSPERIMENTINIO STENDO KAMPINIO POZICIONAVIMO TIKSLUMO TYRIMAS}

\section{Giniotis, D. Bručas}

S a n tra k a

Naudojant daugeli geodeziniu prietaisu svarbu tiksliai išmatuoti kampus. Šiais prietaisais - skaitmeniniais teodolitais, tacheometrais ir kt. - atliekami topografiniai matavimai geodezijoje, matuojama mašinu gamyboje ir kitur. Aprašomas preliminarus stendo, skirto plokščiuju kampu matavimo prietaisams kalibruoti, tikslumo tyrimas; pateikiami vaizdūs apskritiminès skalès tyrimo rezultatai bei kai kurie statistiniai ìverčiai. Formuluojamos išvados dèl tolesnio bandymu stendo tobulinimo.

Prasminiai žodžiai: apskritiminè skalè, matavimas, įvertis, tikslumas, neapibrěžtis. 